\title{
Critical Thinking in the Structure of Educational Programs in Russian Universities
}

\author{
Vitaly Yu. Ivlev ${ }^{1, *}$ Maxim V. Pozdnyakov ${ }^{2, a}$ Vladimir A. Inozemtsev ${ }^{1, b}$ Alexey \\ Z. Chernyak ${ }^{3, c}$
}

${ }^{1}$ National Research University, Bauman Moscow State Technical University (BMSTU), 2-ya Baumanskaya str., 5/1, Moscow 105005, Russia

${ }^{2}$ Federal State Autonomous Educational Institution of Higher Education, Moscow Polytechnic University, Bolshaya Semyonovskaya str., 38, Moscow 107023, Russia

${ }^{3}$ Peoples' Friendship University, Miklukho-Maklaya str., 6, Moscow 117198, Russia

${ }^{a}$ Email:ma2017xim@gmail.com

${ }^{b}$ Email: inozem_63@mail.ru

${ }^{c}$ Email: abishot2100@yandex.ru

*Corresponding author.Email: vitalijivlev@yandex.ru

\begin{abstract}
The article examines the formation of the main approaches to the definition of the concept of "critical thinking", the most important components of critical thinking and the relationship between manipulation of consciousness and critical thinking. The work also studies the formation of critical thinking among students of Russian universities and the development of educational programs in the discipline "Critical Thinking". As the main conclusion, the idea is substantiated that a training course on critical thinking should include the sections, elements of cognitive science, formal logic, the theory of argumentation and a set of information about the methods of manipulating the consciousness of information consumers in the modern information space.
\end{abstract}

Keywords: Critical thinking, Skepticism, Reflective thinking, Educational standards, Educational programs, Manipulation of consciousness, Information space, Logic, Argumentation.

\section{INTRODUCTION}

In this article we intend to consider two interrelated questions: the question of the essence of critical thinking and the question of the place that it should occupy in the design of educational programs of Russian universities. The second question boils down to the following: how should the development of critical thinking be organized (which discipline is responsible for this, and what does it include)? It is advisable to start with the fact that at the moment the term "critical thinking" has at least three meanings: certain mode of thinking (opposed to uncritical or otherwise dogmatic), an

*Fund: The study was carried out with the financial support of the Russian Foundation for Basic Research (RFBR) in the framework of the scientific research project («An innovative environment for the development of gifted students of a technical university in the context of digitalization»). Project № 20-013-00477. interdisciplinary area of research dealing with this phenomenon, and an academic discipline that is taught in a number of universities in the USA, Canada, Europe and some other states including the Russian Federation.

Almost all researchers who analyze contents of educational programs of universities in terms of basic skills that students should acquire, that the urgent task of higher education is to train specialists who are proficient in the methods of independent search, collection, analysis and evaluation of information [1]. We will not repeat all the descriptions of the specificity of the modern informational space. They are already obvious enough. However, in addition to the general recognition that the modern student must be equipped with the ability to live and work in a space saturated with information, the need to consider the declared topic is dictated by a number 
of innovations introduced in the Federal State Educational Standards of Higher Education 3 ++ enacted in December 2017. Instead of the set of general cultural competences (GC) featured in the standards of the previous generation, the concept of "universal competences" (UC) appeared, and categories (groups) of universal competences were introduced. And the first category of these competencies is called "systems and critical thinking". The only competence UC-1 presented in this category describes the specialist as being "capable of searching, critical analysis and synthesis of information, applying a systematic approach to solving the assigned tasks" [2].

In the light of these innovations, it seems important and relevant to reconsider the essence of "critical thinking", since, despite the fact that the content of this concept, apparently, is taken for granted by the authors of these documents, it is far from being clear.

\section{CRITICAL THINKING: FORMING BASIC APPROACHES TO THE TERM'S DEFINITION}

In order to begin a brief survey of points of view on this it is necessary to have at least a preliminary definition of critical thinking. It seems to us that the following one suits this role well: "a conscious effort to determine which statements are correct and which are not" [3]. According to the authors of this definition, it refers to that general feature which the overwhelming majority of researchers agree with.

Critical thinking began to be studied thoroughly in the second half of the 20th century. However, the starting point of these studies, according to a number of authors (Russian and foreign), is the concept of "reflective thinking" introduced into circulation by the American philosopher and theorist of pedagogy John Dewey in the early 20th century. The transformation of this concept resulted in the concept of "critical" thinking.

Thinking in general is defined by Dewey, first, as a transition from a perceived fact or thing present in the external world here and now to other things or facts that are not actually given, that is, as a reference from what is present in perception to what is absent in it, and second, as the formation of confidence in the correctness of such a transition. In this confidence, in turn, two modes are distinguished: the first, in which "a belief is accepted with slight or almost no attempt to state the grounds that support it" [4], and the second, in which "the ground or basis for a belief is deliberately sought and its adequacy to support the belief examined" [5]. This second mode is reflective thinking. Its final definition in the light of what was said by Dewey is the following: "Active, persistent, and careful consideration of any belief or supposed form of knowledge in the light of the grounds that support it, and the further conclusions to which it tends, constitutes reflective thought" [6].

He then analyzes both the very situation of triggering reflective thinking and its mechanism. This is done through the prism of the categories "doubt" and "belief", common to all representatives of pragmatism. The initial situation triggering the reflexive thinking is always constituted by some problem, namely a lack of decisiveness in selecting one of several mutually exclusive opinions - a situation of doubt. It is essential that such a situation should be present in the individual's own experience, he should be personally interested in solving the problem. The next step after the problem was realized is considering certain solution in the form of a selection of a suitable theory. The basis for this is the individual's previous experience and existing knowledge. From them, he extracts material relevant to the situation.

Dewey describes what follows in a perfectly brilliant fragment: "If the suggestion that occurs is at once accepted, we have uncritical thinking, the minimum of reflection. To turn the thing over in mind, to reflect, means to hunt for additional evidence, for new data, that will develop the suggestion, and will either, as we say, bear it out or else make obvious its absurdity and irrelevance. Given a genuine difficulty and a reasonable amount of analogous experience to draw upon, the difference, par excellence, between good and bad thinking is found at this point. The easiest way is to accept any suggestion that seems plausible and thereby bring to an end the condition of mental uneasiness. Reflective thinking is always more or less troublesome because it involves overcoming the inertia that inclines one to accept suggestions at their face value; it involves willingness to endure a condition of mental unrest and disturbance. Reflective thinking, in short, means judgment suspended during further inquiry; and suspense is likely to be somewhat painful. As we shall see later, the most important factor in the training of good mental habits consists in acquiring the attitude of suspended conclusion, and in mastering the various methods of searching for new materials to corroborate or to refute the first suggestions that 
occur. To maintain the state of doubt and to carry on systematic and protracted inquiry - these are the essentials of thinking" [7].

We see that for Dewey the essential features of reflective thinking is conscious refraining from passive acceptance of the first conclusion that comes to mind as true and the willingness to endure this unpleasant state, filling it with methodical efforts to find new considerations that confirm or refute this first conclusion.

Dewey's considerations outlined above will be enough to move on to more modern approaches. At the same time, our tasks do not include full overview of all of them. It is important for us to get an idea of the framework of critical thinking.

The considered work of Dewey was published in 1910. The closest milestone in his consideration of critical thinking comes from a 1941 work by Edward Glazer. In it he reduces critical thinking to three basic elements: "1) an attitude of being disposed to consider in a thoughtful way the problems and subjects that come within the range of one's experiences, 2) knowledge of the methods of logical inquiry and reasoning, 3) some skill in applying those methods" [8].

This list is further expanded into a more extensive list of skills and abilities: "Critical thinking calls for a persistent effort to examine any belief or supposed form of knowledge in the light of the evidence that supports it and the further conclusions to which it tends. It also generally requires ability to recognize problems, to find workable means for meeting those problems, to gather and marshal pertinent information, to recognize unstated assumptions and values, to comprehend and use language with accuracy, clarity, and discrimination, to interpret data, to appraise evidence and evaluate arguments, to recognize the existence (or non-existence) of logical relationships between propositions, to draw warranted conclusions and generalizations, to put to test the conclusions and generalizations at which one arrives, to reconstruct one's patterns of beliefs on the basis of wider experience, and to render accurate judgments about specific things and qualities in everyday life" [9].

From this list it becomes clear that critical thinking, according to Glazer, includes a range of knowledge constituting the subject of logic and, correspondingly, the development of the ability to apply this knowledge in practice. The fact that such an understanding almost immediately became a commonplace is demonstrated by the content of dozens of textbooks on critical thinking, in which great attention is paid to the coverage of these issues.

An important component of critical thinking, pointed out by a number of researchers (Sears, Parsons, Halpern), is the presence of an attitude towards its application. A subject who begins to consider any information, and at the same time is confident that he is able to think critically, should not only have knowledge of logic - he should want, so to speak, to turn on this mechanism in the current situation. At the same time, this attitude, according to D. Halpern, in turn implies a number of personal qualities of this subject: readiness for planning, flexibility, persistence, readiness to correct mistakes, awareness (metacognition), search for compromise solutions [10]. Accordingly, training in critical thinking should be structured so that, on the one hand, the subject develops these qualities in himself in principle, and, on the other hand, learns to use them situationally.

The statement of the importance of the presence of the described attitude, as well as the opening of the subqualities that form it, makes it possible to establish a number of reasons why critical thinking is not used by the subject. First, the listed subqualities themselves may either be absent altogether, or be poorly expressed. Second, the application of these sub-qualities, putting them into operation, requires effort, is accompanied by the expenditure of much more energy than uncritical thinking. Hence the simplest explanation of why a large number of people (even those with higher education) prefer the latter. They simply do not want to waste their energy on critical thinking. In order to "creak your brains" after graduating from a university, working day after day, and solving everyday tasks in addition to work, besides having a family, you need to have this free energy. And, as a rule, there is none. And it turns out that the subject, whose energy saving mode turns off the critical thinking mindset, falls into the open arms of the media, which have their own reasons and methods for cheating him.

A number of researchers (Flavell, Langer, Pintrich, Tuckman) point to another component that is necessarily part of critical thinking. This component is called "metacognition". The term was introduced into circulation by J. Flavell [11]. This term refers to the tracking by a thinking subject of the process of his own thinking, awareness of what links it consists of, and how it proceeds. A person, 
in whose thinking there is no such component, is not aware of how he comes to some conclusion or decision, uses ready-made templates, not understanding their origin and the boundaries of their applicability.

\section{MIND MANIPULATION AND CRITICAL THINKING}

Now we came to a very important component of critical thinking, which attracts unfairly little attention little within the analysis of this matter. We considered critical thinking from the point of view of its structure and importance for the subject, acting as a consumer of some information which he applies the specified ability to. Now it is necessary to point out the following obvious circumstance. Behind the information reported are always individuals, groups and organizations that, among other things, can deliberately use methods of misleading the recipient, misinform him and purposefully try to turn off his critical thinking. It is equally obvious that the construction of an illusory picture of the world is aimed at achieving benefits of one kind or another in various segments of social life: political, economic, commercial, spiritual, and others. We are talking about the so-called mind manipulation. It's successful definition in the light of the topic under discussion is the following: "the technology of overcoming critical reflection of individuals, instilling in them the ideas, goals and values set by the manipulator as the basis for the reproduction of social practices" [12].

This definition directly states that the purpose of manipulation is precisely the suppression of critical thinking. The general principles and methods of such work with infospace have already been described many times. In addition, foreign and Russian researchers have already considered hundreds of examples of how this was done on various occasions, and it has been shown exactly what benefit final stakeholders and interested parties gain. It is not our task to describe these methods themselves. Suffice it to mention at least two similar monographs available in Russian: the textbook work by G. Schiller that has not lost its relevance [13], based on American material, and the study of this issue by the Russian author $\mathrm{S}$. Kara-Murza on domestic material [14]. An interested reader may be advised to refer to them.

We are interested in how the fact that the consciousness of the consumer of information is manipulated is refracted in the topic under consideration. On the one hand, it is clear that it is critical thinking that should reveal these manipulations and break through them. For example, D. Halpern writes: "In reality, critical thinking is an antidote to the very thought control that worried Orwell. Learning the skills of clear thinking can help everyone to recognize propaganda and thereby not become a victim of it ..." [15]. On the other hand, manipulation works to paralyze it.

The real problem is that all of the above components of critical thinking sometimes do not work against manipulation, protection can only be provided if the subject of critically thinking is familiar with the principles and common methods of such manipulations. This is specific information, it forms a special group, and those who benefit from it (politicians, heads of corporations, media owners, etc.) are not interested in their wide publicity, in the first place; all these people, as a rule, have the resources to conceal such knowledge from the bulk of the population. Thus, an interesting situation arises: you can teach critical thinking, introduce appropriate courses into educational programs, but if these issues are not covered in the process of such training, then the result will be a tool that lacks the most important detail. This tool will work, but it will turn off where it is needed most of all.

In our opinion, there is one more difficulty - in order to identify manipulation (at least just to feel that there is hidden control), there is not enough to know how this is done in principle - it is necessary first to pose and then answer the question: who is the ultimate beneficiary of its use. What minimal level of complexity of manipulation is necessary condition for this is a matter of discussion, but the events of literally the last couple of years demonstrate that now this practice is no longer an intellectual luxury - without it, it is no longer possible to figure out whether you are being fooled.

Once again, notice that some manipulations can be exposed only by discovering the beneficiaries, and vice versa, the presence of the beneficiaries in the shadows is realized by the subject only when he felt that the conclusion that he is about to draw (from what he heard, saw, or read) is being made not by, but sort of in him. In most cases, this realization does not occur. This is the art of manipulation. It remains only to subscribe to the remark made by V.V. Rokotyanskaya in her article: "Internet manipulations of public opinion should take place imperceptibly and not arouse even minimal suspicion: a person should come to the 
conclusion that he himself makes this conclusion on a certain issue. This is how critical thinking is put to sleep" [16]. In this case, it is no longer just about manipulations (the invisibility of such was already pointed out by Schiller in his 1973's work), but about Internet manipulations. The networked information space, which until a certain point was an alternative to traditional media, is now itself a powerful generator of disinformation and an arena for manipulation.

Realization that there is a stakeholder behind the promotion of specific information and discovery of that stakeholder is perhaps the most subtle part of the use of critical thinking. Without this skill, we get a tool with truncated functions. From what has been said, it directly follows that the training program for critical thinking should include a segment in which the theories of the methods of mind manipulation are observed, and the importance of identification of beneficiaries is stressed.

\section{PRELIMINARY RESULTS}

Let us summarize a certain intermediate result in terms of the set of elements that make up the sought-for framework of critical thinking. Its central element, the core that distinguishes it from the uncritical (dogmatic) thinking, is skepticism. Any information on the problem to be resolved, any information, acquaintance with which implies the formation of a position or opinion, entering the field of view of a critically thinking subject, cannot be recognized as reliable without comparison with facts, or (if the facts are not available) verification of its origin; without a doubt that this information is correct, and therefore it is possible to rely on it. Two things follow from this.

First, a critically thinking subject is obliged to raise the question about the source of information and the degree of its validity. This is the foundation of critical thinking, recognized as such by all researchers, traces of which can be found in many definitions of this concept. At the base of critical thinking lies the law of sufficient reason, formulated by Leibniz, which denies that judgment is true in the absence of a sufficient degree of its validity. Here is the definition of V.N. Bryushinkin, which is quite often cited in domestic studies. According to his approach, critical thinking is “... a sequence of mental actions aimed at checking statements or systems of statements in order to clarify their inconsistency with the accepted facts, norms or values" [17].
Second, if the material for the application of critical thinking is some conclusions, inferences, then it should ask the question of their compliance with the requirements of logic. It obviously follows from this that a subject who does not have an idea of how logically correct reasoning is built, even with all his desire to think critically, will not be capable of this.

What skills should be acquired to provide training in critical thinking? From the foregoing it follows that they should be reduced to the following list:

- a) the general attitude to a reasonable amount of skepticism regarding the incoming information;

- b) a block of skills consisting in operating concepts (to be aware of their content, to carry out their definitions, to establish relationships between concepts);

- c) a block of skills associated with inferences (identifying the structure of inferences, their type, establishing the presence or absence of a relationship of logical following or confirmation;

- d) identification of errors in inferences;

- e) a block of skills related to argumentation (identifying its structure, building one's own argumentation or counterargumentation, evaluating a specific model of argumentation for its correctness, identifying methods of incorrect argumentation);

- $\mathrm{f})$ asking the right questions and formulating the correct answers;

- $\quad$ g) fixation of the fact of mind manipulation carried out in the media or other channels of information flow, identification of the applied methods of disinformation;

- h) the ability to raise the question about explicit or hidden beneficiaries of the consumption of any information as reliable, the ability to at least roughly outline the circle of these persons.

\section{TEACHING STUDENTS THINK CRITICALLY IN RUSSIAN UNIVERSITIES}

Now it is necessary to deal with the problem of the best ways of providing the development of critical thinking by students at Russian universities. There are two possible solutions to this issue. The first one boils down to the fact that such thinking is 
formed in students in the process of studying any (profile or non-core) discipline, that is, teachers solve this problem every time in relation to the specifics of the subject taught by them. The second approach is that the student gains insight into critical thinking from a specialized discipline. It can bear the same name, or the term "critical thinking" may be included in the name as an integral part. The first approach is expressed, for example, in the article by Yu.A. Karpushina and O.Yu. Ivanova. Regarding the competence of UC-1, they write: "The fact that the formation of systemic and critical thinking is the leading requirement of the $\mathrm{CC}$ is indisputable. GK-1 "Formation of an ideological position on the basis of philosophical knowledge" gave way to UC-1, which is the first and fundamental competence from the entire set of UCs. The educational process in any area of undergraduate studies should be structured so that UC-1 is formed by each academic discipline throughout all stages of training" [18].

Recall that UK-1 boils down to the wording "capable of searching, critical analysis and synthesis of information, applying a systematic approach to solving the assigned tasks" and is included in the category of "systemic and critical thinking", in which there is nothing else besides this competence.

A similar opinion is expressed in the article by V.D. Vasilyeva. Using the example of the specialty 09.03.01 "Informatics and Computer Engineering", the author binds universal competencies to certain social and humanitarian disciplines that should develop them. At the same time, UK-1 is not tied to any of them. Among these disciplines, in particular, "Psychology of professional activity" appears, which simply begs for this role, but, according to the author, it is responsible for other universal competencies. This indicates that the development of the UC-1 is thought by the author as the task of the disciplines directly responsible for professional competencies. The article does not speak about this directly, but no other conclusion can be seen [19].

The second option (the presence of a separate discipline in the curriculum) seems to us preferable. First, because it does not exclude the former, due to the fact that any specialized discipline really contributes to the development of skills for critical handling of information related to the subject of this discipline. However, in the absence of a special academic subject that considers the very phenomenon of critical thinking, the student is deprived of a clear idea of its content, what it is based on, how it functions, and what requirements must be obeyed. In addition, a teacher of specialized subjects is unlikely to place a special emphasis on increasing critical thinking, as well as to have time to focus the student's attention on the phenomenon itself, including, as has already been shown, a fairly large array of information. It is appropriate to cite the considerations of G.V. Sorina, who writes: "At the same time, one of the most important features of critical thinking is that it teaches the analysis and construction of reasoning, the acquisition of knowledge, regardless of the professional field of activity" [20].

That is, the advantage of the second approach consists in that, first, the student's attention is focused on the phenomenon itself, second, the student receives an array of information about the content of the phenomenon, and third, he is given the attitude and skills to apply critical thinking to any received information that he may come across. In addition, in Western universities the choice was unambiguously made in favor of the second approach - the introduction of a special discipline into the curriculum.

\section{CONCLUSION}

Now we can summarize what kind of knowledge and skills should be included in such a program.

How should a critical thinking curriculum be structured? Taking into account what was said earlier about the skills that form critical thinking, in our opinion, it should consist of the following sections or blocks. In the first part of the first section, a general idea of the structure of the cognitive abilities of people should be given. Of course, already at this stage it will be necessary to give at least a preliminary definition of "critical thinking". In the same part, it is advisable to highlight the circumstances that complicate the correct application of thinking in principle. Among other things, it should be about the circumstances identified by the classics of philosophy when discussing epistemological issues: F. Bacon, J. Locke and other thinkers, and the circumstances identified by modern cognitive science, including cognitive psychology.

The next part of the first section is devoted to the specifics of the modern information space, which has not been described by any classics, and creates for an individual facing it either new or strongly transformed old challenges. 
The second section is nothing more than formal logic in its main topics and subtopics. It is impossible to conduct any consideration of critical thinking without having knowledge of what this thinking consists of.

The third section is formed by the theory of argumentation.

The fourth section consists of information about the methods of mind manipulation applied to information consumers in the modern infospace, that is, about a deliberate strategy and tactics of disinformation and covert control of thinking and behavior.

\section{AUTHORS' CONTRIBUTIONS}

Vitaly Ivlev: Participated in editing a draft version of the article; Approved the final version of the article for publication; Agreed to be responsible for all aspects of the study that may raise questions related to its accuracy, integrity and credibility.

Maxim Pozdnyakov: Made a significant contribution to the design and development of the study design; Participated in writing a draft version of the article; Approved the final version of the article for publication; Agreed to be responsible for all aspects of the study that may raise questions related to its accuracy, integrity and credibility.

Vladimir Inozemtsev: Made a significant contribution to the collection, analysis and interpretation of data; Participated in writing a draft version of the article; Approved the final version of the article for publication; Agreed to be responsible for all aspects of the study that may raise questions related to its accuracy, integrity and credibility.

Alexey Chernyak: Participated in editing a draft version of the article; Approved the final version of the article for publication; Agreed to be responsible for all aspects of the study that may raise questions related to its accuracy, integrity and credibility.

\section{REFERENCES}

[1] M.L. Ivleva, N.L. Bagramyants, V.Yu. Ivlev. Discussion on some features of innovative system of professional training (ICELAIC 2018) // Proceedings of the 5th International Conference on Education, Language, Art and Inter-cultural Communication. Advances in Social Science, Education and Humanities Research, vol. 289, pp.14-19

[2] FGOS VO 3 ++ URL: https://fgosvo.ru
[3] N.M. Daud, Z. Husin. Developing Critical Thinking Skills in Computer-Aided Extended Reading Classes // British Journal of Educational Technology. 2004. Vol. 35. № 4. P. 477-488. - P. 479.

[4] J. Dewey. What is thought? Lexington, Mass: D.C. Heath. 1910. - P.1.

[5] J. Dewey. What is thought? Lexington, Mass: D.C. Heath. 1910. - P. 1-2.

[6] J. Dewey. What is thought? Lexington, Mass: D.C. Heath. 1910. - P. 6.

[7] J. Dewey. What is thought? Lexington, Mass: D.C. Heath. 1910. - P. 13

[8] E. Glaser. An Experiment in the Development of Critical Thinking. Teachers College, Columbia University, 1941. - P.14.

[9] E. Glaser. An Experiment in the Development of Critical Thinking. Teachers College, Columbia University, 1941. - P.15.

[10] D. Halpern. Psychology of critical thinking. $\mathrm{SPb}$ : Peter, 2000.

[11] J.H. Flavell. Meta cognition and cognitive monitoring: A new area of cognitive developmental inquiry. American Psychologist. 1979. Vol. 34. №10. P. 906 911.

[12] O.N. Kozlova. Manipulation of consciousness and subjectivity in the XXI century // Bulletin of the Russian State University for the Humanities. 2010. Series "Philosophy. Sociology". No. 3. P. 113 - 120. - P. 114.

[13] G. Schiller. Manipulators of consciousness. M.: Thought, 1980.

[14] S.G. Kara-Murza. Consciousness manipulation. M.: Eksmo, 2005.

[15] D. Halpern. Psychology of critical thinking. SPb: Peter, 2000. - P. 24.

[16] V.V. Rokotyanskaya. Management of public opinion in modern Russia // Problems of Economics and Legal Practice. 2018. No. 5. P. 43 - 47. - P. 47.

[17] V.N. Bryushinkin. Critical thinking and argumentation // Critical thinking, logic, argumentation. Kaliningrad: KSU Publishing House, 2003. P. 29 - 34. - P. 30. 
[18] Yu.A. Karpushina, O.Yu. Ivanova. On the problem of formulating universal competences of the Federal State Educational Standard of Higher Education 3 +++ (bachelor's level) // Scientific notes of the Oryol State University. 2019. No. 2 (83). P. 239 - 242. - P. 240.

[19] V.D. Vasilyeva. Social and humanitarian disciplines of engineering training in the aspect of FGOS VO $3++/ /$ Higher education in Russia. 2019.Vol. 28.No. 4. P. $111-119$.

[20] G.V. Sorina. Critical thinking: history and current status // Bulletin of Moscow University. 2003. Series 7. Philosophy. No. 6. P. 97 - 110. - P. 108. 